\title{
Screening for Mental Health Problems in Epidemics: Is It Justifiable?
}

\author{
Vandad Sharifi, $\mathrm{MD}^{1}$; Atefeh Mohammadjafari, $\mathbf{M D}^{1^{*}}$ \\ 'Department of Psychiatry, Tehran University of Medical Sciences, Tehran, Iran
}

\begin{abstract}
Background: Given the overwhelming mental health consequences of infectious epidemics, timely identification and treatment of people with mental health problems is essential. In this narrative review, screening instruments and procedures for identification of mental health problems at the time of epidemic crises are reviewed and the results are discussed in the context of our experience in the recent COVID-19 epidemic in Iran.

Methods: Forty studies were retrieved from searches in several databases which used screening procedures for identification of mental health conditions during infectious epidemics.

Results: Studies were performed on three groups of health care workers, at-risk general population, and patients with confirmed/ suspected infection, using a wide range of instruments. Most have used screening instruments for the purpose of prevalence estimation and only 5 have included it as a health intervention while none has investigated its effectiveness.

Conclusion: The evidence base for screening at the time of epidemics is weak. If it is used to identify the needs and enhance help seeking, the screening instruments should have adequate psychometric properties; moreover, their integration in the available services is strongly recommended. Original studies are needed to investigate the usefulness of mental health screening programs in crises such as the COVID-19 epidemic.

Keywords: COVID-19, Epidemic, Identify, Iran, Mental health, Screening

Cite this article as: Sharifi V, Mohammadjafari A. Screening for mental health problems in epidemics: Is it justifiable?. Arch Iran Med. 2021;24(8):643-650. doi: 10.34172/aim.2021.91
\end{abstract}

Received: July 27, 2020, Accepted: March 9, 2021, ePublished: August 1, 2021

\section{Introduction}

Crises such as floods, earthquakes, plane crashes, and notably, epidemics can have long-lasting mental health consequences. In December 2019, a novel coronavirus (COVID-19) epidemic outbreak was reported in China which shortly transformed into an unprecedented pandemic. In this pandemic, the general population, health care workers and infected patients and their relatives are exposed to a range of traumas and stressors. ${ }^{1-3}$ Fear of spreading the disease, stigma and anxiety related to infection, maintaining physical distance, uncertainty about the current circumstances, and consequent economic burden can trigger negative psychological response. ${ }^{4,5}$ In several studies, higher levels of psychological tensions, depression, anxiety, traumatic stress, and declines in quality of life are reported in populations for months or even years after the pandemic has ended. ${ }^{6,7}$ On the other hand, high workloads, witnessing high numbers of deaths, inability to control the situation, constant changes in the knowledge regarding the infection and concerns about infecting their own families lead to high rates of psychological distress among healthcare workers. ${ }^{6}$ Several studies have shown that healthcare workers experience mental health problems such as anxiety, depression, posttraumatic stress disorder (PTSD), high levels of alcohol and cigarette consumption, and job leaves for months or even years afterwards. ${ }^{8-10}$ However, many of those with mental health problems do not seek or receive effective psychological and psychiatric services, perhaps because of stigma, lack of proper mental health knowledge or difficulty in accessing services. Moreover, many, even policy makers, may not consider mental health as a priority in an epidemic. ${ }^{11}$

Given the high rates of mental health problems after these crises, there is a remarkable need for timely identification and treatment of people with these problems. ${ }^{12,13}$ This has several advantages: First, some people may not be aware of suffering from these problems or do not know how to get treatments. Second, detection of problems can be useful for planning the services and providing the targeted interventions. Thus, in addition to applying universal interventions and providing educational and preventive services to the general population and at-risk people, it is necessary to take measures for identification of mental health problems and psychiatric disorders during and after such epidemics.

Different methods are available for identification of mental health problems. Applying screening instruments have a long history in mental health. Some have advocated their useand argued that these measures mayhelp to identify and link those with the conditions to the services. ${ }^{14,15}$ Yet, its benefits during disasters, including epidemics, are still 
unknown and there are some important issues to consider before any screening in the time of crises. In this article, the characteristics of appropriate tools for identification of people with mental health and psychiatric problems in different groups in infectious diseases' epidemics are reviewed and discussed in a narrative manner. The results were discussed in the context of our experience in the recent COVID-19 epidemic in Iran which has taken the lives of hundreds of people so far and has imposed a huge health, social and economic burden on families and communities. Although Iran has made many efforts to control the outbreak, it faces big challenges to combat the infection at the same time, including some of the toughest sanctions imposed on a country in the world. ${ }^{16}$

\section{Materials and Methods}

Searches were conducted in Google Scholar, Springer and PubMed databases in July 2020 with the following keywords and their various combination: "severe acute respiratory syndrome”, "SARS”, “coronavirus”, "covid-19”, "psychological", "mental", "Ebola”, "Influenza", "Middle east respiratory syndrome", "MERS" and "epidemics". Searches were conducted on the title and the abstract of citations and then full-text articles were assessed. The references of retrieved citations were also searched manually. Only English-language articles were selected for the review. For study selection, studies that used tools for studying prevalence and/or screening of mental health problems in epidemics were included. Finally, 40 articles were included in the study. Studies had different sample populations; so, they were assessed in three groups of atrisk general population, health care workers and patients with infectious diseases.

\section{Results}

Of 40 included articles, the sample population was at-risk general population in 22 studies, health care worker in 23 studies and patients with infectious diseases in 9 studies. Studies were on SARS (5 studies), MERS (5 studies), COVID-19 (20 studies), H1N1 influenza (2 studies) and Ebola (3 studies) epidemics. Only 5 studies specifically assessed the screening process as a health intervention (Table 1) and none investigated the effectiveness and efficiency of the screening procedure in help seeking and mental health outcomes. The aim of the rest was studying the prevalence of mental health problems and their correlates.

\section{General Considerations for Screening in Epidemics}

Various tools were used for screening, including questionnaires, either self-administered or interviewbased, and most of them could be completed through remote assessment. Several authors suggested that screening should be a component of a general mental health interventions' program which in turn can be integrated in a general health interventions' program to minimize the rates of infection and lack of mental interventions. ${ }^{11,12,14,15,17}$ It is recommended that screening should not disrupt the process of providing medical and social services and should be undertaken during the epidemic and repeated at particular intervals. ${ }^{1,14}$ The recommended characteristics of proper tools and procedures for screening are enlisted in Box 1.

\section{Screening the At-risk General Population}

The focus of interventions for the general population is generally on raising awareness and education about ways of maintaining mental health during epidemics, while active screening for mental health conditions is rare and most studies are conducted for the purpose of prevalence estimation. ${ }^{11}$ Several methods have been used for screening and assessment of psychological problems at these times. The most common examples include online questionnaires $^{45}$ with available national platforms $s^{29,51}$ or through e-mails, ${ }^{46}$ screening through community-based mental health centers ${ }^{52}$ or primary care centers ${ }^{26}$ via telephone or during visits at the clinics, and completion of self-administered questionnaires through random phone calls in the region afflicted by epidemics. ${ }^{43,52}$ In the recent coronavirus epidemic in China, artificial intelligence was used for detection of messages indicating psychiatric emergencies such as suicide in the platforms and informing responsible person ${ }^{21}$ which were followed by necessary interventions. Some studies on long-term effects of epidemics performed in-person or telephone

Box 1. Recommended Features of Screening Instruments and Procedures for Mental Health Problems During Epidemics

Recommendations for the screening tools:

- $\quad$ They should be short and easy to complete. ${ }^{14,15}$

Their original and local versions should have adequate reliability, specificity,

sensitivity, and positive predictive value indices. ${ }^{14,15}$

- $\quad$ Those that detect general distress or any mental health problem and are not limited to specific mental health problems are preferred. ${ }^{14}$

Recommendations for screening application procedures:

- They can be self-administered; alternatively, they can be easily conducted via telephone or through online platforms. ${ }^{15}$

- $\quad$ Can be easily implemented. ${ }^{14}$

- Information can be kept confidential, particularly in online platforms. ${ }^{14}$

- Face-to-face situations should be avoided; online or remote ways are preferred. . $^{12,21}$

- Conducted periodically even after epidemics have ended. ${ }^{6,7}$ 
Table 1. Screening Instruments Used in Prevalence/Interventional Studies in Epidemics

\begin{tabular}{|c|c|c|c|c|c|c|c|}
\hline Instrument & $\begin{array}{l}\text { No. of } \\
\text { Items }\end{array}$ & $\begin{array}{l}\text { Completion } \\
\text { Time }\end{array}$ & $\begin{array}{l}\text { Used in } \\
\text { COVID-19 }\end{array}$ & $\begin{array}{l}\text { Used in At- } \\
\text { risk General } \\
\text { Population }\end{array}$ & $\begin{array}{c}\text { Used in } \\
\text { Suspected or } \\
\text { Infected Patients }\end{array}$ & $\begin{array}{l}\text { Used in } \\
\text { Healthcare } \\
\text { Workers }\end{array}$ & References \\
\hline \multicolumn{8}{|c|}{ General distress/psychopathology } \\
\hline GHQ-9 & 9 & $3-5$ & $\checkmark$ & $\checkmark$ & $\checkmark$ & $\checkmark$ & $\begin{array}{c}12^{*}, 17^{*}, 18,19,20,21,22 \\
23,24,25\end{array}$ \\
\hline GHQ 28 & 28 & $5-10$ & & $\checkmark$ & & & 26 \\
\hline GHQ-12 & 12 & $3-5$ & & $\checkmark$ & & & 27,28 \\
\hline K10 & 10 & $3-5$ & & $\checkmark$ & & $\checkmark$ & 29,30 \\
\hline K6 & 6 & $2-5$ & $\checkmark$ & $\checkmark$ & $\checkmark$ & & $31 * 32$ \\
\hline PSS-10 & 10 & $<10$ & & $\checkmark$ & $\checkmark$ & $\checkmark$ & $33,4^{*}, 34$ \\
\hline HADS & 14 & $2-5$ & & & $\checkmark$ & & 9 \\
\hline DASS-21 & 21 & $<10$ & $\checkmark$ & $\checkmark$ & & & $35,36,37$ \\
\hline SCL90-R & 90 & $20-25$ & & & $\checkmark$ & $\checkmark$ & 38,39 \\
\hline \multicolumn{8}{|l|}{ Anxiety conditions/disorders } \\
\hline GAD-7 & 7 & $<5$ & $\checkmark$ & $\checkmark$ & $\checkmark$ & $\checkmark$ & $12^{*}, 21,40,18,41,19,20,25$ \\
\hline DAQ & 15 & $2-6$ & & $\checkmark$ & & & $4^{*}$ \\
\hline SAS & 20 & $<10$ & & & & $\checkmark$ & $42^{*}$ \\
\hline CAS & 25 & $5-10$ & & $\checkmark$ & & & 43 \\
\hline HAMA & 14 & $10-15$ & & & & $\checkmark$ & 44 \\
\hline \multicolumn{8}{|l|}{ Depressive conditions/disorders } \\
\hline CESD & 20 & $5-10$ & & $\checkmark$ & & & $4^{*}, 45,34$ \\
\hline Mood Index Questionnaire & 20 & 50 & $\checkmark$ & $\checkmark$ & $\checkmark$ & $\checkmark$ & $12^{*}$ \\
\hline SDS & 20 & $<10$ & & & & $\checkmark$ & $42^{*}$ \\
\hline HAMD & 17 & $20-30$ & $\checkmark$ & & & $\checkmark$ & 44 \\
\hline \multicolumn{8}{|c|}{ Traumatic stress conditions/disorders } \\
\hline IESR & 22 & $5-10$ & $\checkmark$ & $\checkmark$ & $\checkmark$ & $\checkmark$ & $\begin{array}{c}45,46,26,35,37,8,47,9 \\
48,49,21,22,36\end{array}$ \\
\hline IES & 15 & $5-10$ & & & & $\checkmark$ & $50,23,30$ \\
\hline PCL-5 & 20 & $5-10$ & $\checkmark$ & $\checkmark$ & & & 51 \\
\hline ASDS & 19 & $5-10$ & $\checkmark$ & $\checkmark$ & & & 20 \\
\hline \multicolumn{8}{|l|}{ Others } \\
\hline PSQI & 19 & $5-10$ & $\checkmark$ & & $\checkmark$ & $\checkmark$ & $12 *, 51,42 *$ \\
\hline The Insomnia Severity Index & 7 & 3 & $\checkmark$ & & & $\checkmark$ & $21,41,22,25,20$ \\
\hline SF12 & 12 & $<5$ & $\checkmark$ & $\checkmark$ & & & 32 \\
\hline SWLS & 5 & & $\checkmark$ & $\checkmark$ & & & 32 \\
\hline STAXI & 10 & 10 & & $\checkmark$ & & & 40 \\
\hline Oss & 3 & $1-2$ & & & $\checkmark$ & & 28 \\
\hline MBI-EE & 22 & $10-15$ & $\checkmark$ & & & $\checkmark$ & $51,24,45,30$ \\
\hline
\end{tabular}

GHQ, General Health Questionnaire; PSS-10, Perceived Stress Scale; HADS, Hospital Anxiety and Depression Scale; DASS-21, The Depression, Anxiety and Stress Scale; BSRS-5, The five-item Brief Symptom Rating Scale; SCL90-R, The Symptom Check List 90 - Revised; GAD-7, Generalized Anxiety Disorder 7-item; DAQ, Death Anxiety Questionnaire; SAS, Zung's Self-rating Anxiety Scale; CAS, Clinical Anxiety Scale HAMA, Hamilton Anxiety Scale; CESD, Center for Epidemiologic Studies Depression Scale; SDS, Zung's Self-rating Depression Scale; HAMD, Hamilton Depression Scale; IESR, Impact of Event Scale - Revised; PCL-5, The PTSD Checklist for DSM-5; ASDS, Acute Stress Disorder Scale; PSQI, The Pittsburgh Sleep Quality Index; SF12, Short-Form Health Survey; SWLS, The Satisfaction With Life Scale; STAXI, The State-Trait Anger Expression Inventory; OSS, Oslo Social Support Scale; MBI-EE, Maslach Burnout Inventory.

*Used as a screening tool in an interventional study.

screening programs several months after the epidemic had ended. ${ }^{40}$ Out of these studies, few evaluated the provision of mental health services after screening. ${ }^{17,21,52}$ As an exception, during the MERS epidemic in South Korea, screening was conducted via telephone in $99.6 \%$ of quarantined individuals and only $0.3 \%$ were in-person. For individuals with positive results, psychological support and education and interventions were provided through community mental health centers. ${ }^{52}$

In addition to the commonly used screening instruments, some special tools were designed for mental health issue related to the COVID-19 epidemic, such as the Coronavirus Anxiety Scale (CAS), the Obsession with COVID-19 Scale (OCS), the Fear of COVID-19 Scale 
(FCV-19S), and the COVID Stress Scales (CSS)..$^{53}$ Tools used for the assessment of prevalence and screening instruments are listed in Table 1.

\section{Screening Healthcare Workers}

Screening of medical personnel has been conducted by various measures such as online platforms which became particularly prominent in the recent coronavirus epidemic, given the advances in internet access and smartphones, ${ }^{12,21,22}$ e-mails, ${ }^{9,50}$ telephone, ${ }^{12}$ attending pavilions, ${ }^{12}$ in-person interviews ${ }^{54}$ and through in-person visits and paper questionnaires after the end of influenza and SARS epidemics. ${ }^{55,56}$ Here again, most studies were performed for the sake of epidemiologic investigations rather than for the screening per se. Table 1 presents the tools used in these studies conducted during epidemics.

\section{Screening People with Confirmed or Suspected Infections}

In epidemic crises, patients with a confirmed or suspected infection experience mental health problems due to concerns about being infected or transmitting the infection, isolation in quarantine, and other factors such as delirium, drug adverse effects, etc. Due to prioritizing medical treatments, stigma and improper communication between patients and medical teams, it is highly possible that mental health problems are left undetected and thus, patients do not benefit from mental health care. Therefore, case identification in this group of population is of utmost importance.

Since the probability of infection is high in these centers and face-to-face assessment is not advised, evaluation and screening of these patients should be integrated into the current medical system ${ }^{11,12,14}$ and assessments can be done via online platforms or through telephone conversations. ${ }^{12}$ In some studies, assessment of this group of the population is postponed to a later time after discharge and recovery of patients from the infectious disease which is conducted as in-person visits, telephone follow-up or e-mails. ${ }^{6}$ The results of studies show that patients who recover from the disease experience mental health problems in the long term. ${ }^{6}$ In previous epidemics such as SARS, Ebola and influenza, in-person assessment of patients for psychological problems was used very infrequently. ${ }^{28,57}$ Table 1 enlists some tools for screening and assessment of the prevalence of psychological problems among patients during epidemics.

\section{Discussion}

This review showed that most studies used screening instruments for the purpose of prevalence estimation and studies which employed it as part of a health intervention for identification of those with mental health problems were scant and none evaluated its effectiveness. This alone shows that the evidence base for the utility of screening instruments during epidemics and other disaster situations is weak and needs to be strengthened.

However, there are some important points to consider before any screening procedure: First, screening instrument should have valid psychometric properties for the target population. Second, the instrument must have the ability and application for use in the times of crises and disasters. For instance, in pandemics, general screening tools which assess psychological distress may be more beneficial compared to specific PTSD measures which are more commonly used for particular traumas such as floods and earthquakes. Third, it is best to integrate any screening procedure into the available services; in addition, the procedures should be practical, acceptable, and not disrupt the process of medical service delivery. Fourth, given the high rates of mental health problems and psychiatric disorders, it must be noted that the screening can convert an unmet need into an unmet demand. ${ }^{14}$ Thus, prior to initiation of any screening, the available facilities and resources should be assessed to ensure the feasibility of providing interventions based on the screening results. Due to false positive cases in screening programs, particularly in conditions with high prevalence rates, screening can be conducted via a 2-step process; for instance, a confirmatory interview is performed after initial screening to rule out false positive cases, and determine the needed service (educational, therapeutic, etc). ${ }^{17,42,52,54}$ Fifth, under the circumstances of infectious epidemics, face-to-face screening is not appropriate and therefore, choosing a proper tool and its application through remote and online platforms takes priority. In the coronavirus epidemic in China, the rate of online psychological interventions was increased and the efficacy and quality of these interventions were improved. ${ }^{21}$ Below, we briefly provide our experience with the implementation of screening procedures in some settings in Iran during the COVID-19 outbreak.

\section{Screening in the COVID-19 Crisis: An Experience from Iran}

In Iran, the coronavirus outbreak started in February 2020; as of late July, it has infected up to 290000 individuals and resulted in more than 15000 deaths according to the official reports. ${ }^{58}$ Since its outset, the Department of Psychiatry in Tehran University of Medical Sciences developed and implemented a program for its teaching hospitals which are among the major COVID-19 referral centers in Tehran, the capital city of Iran, as well as the larger community in the country. The program is based on the evidences and experiences from similar crises in Iran and other countries while considering the specific circumstances of the country for mental health interventions in the COVID-19 crisis. Interventions were considered at three levels: (a) psychological education aimed at prevention and promotion of mental health for general population, patients, personnel and authorities; (b) supportive and preventive services for first-line healthcare workers; and $(c)$ interventions for medical staff and patients with mental health problems with or without a previous psychiatric history. In this program, the top 
priority was given to interventions for first-line healthcare workers and patients with the infection while patients' relatives and the general population were considered as the next priorities in the first wave of the epidemic. Since patients with COVID-19 have a relatively short hospital stay, medical treatments were the first priority during hospitalization, and in-person psychological intervention was impractical while technological alternatives such as remote counseling was not available in many settings; therefore, the team decided to pass the primary focus of interventions onto the medical staff. Although supportive and resilience groups were employed for preventive purposes, it seemed that a large proportion of medical staff were experiencing severe work burnout and development or relapse of psychiatric disorders.

However, despite sending notices about the availability of psychological and psychiatric services, either remote or in-person, very few presented at the clinic or used the services which probably resulted from stigma, inadequate time or unawareness about the presence of a mental health condition, and availability and access to treatments. Therefore, our colleagues in several university-affiliated hospitals decided to implement screening for identification of mental health conditions among first-line healthcare workers. Thus, instruments for online screenings were employed in three hospitals of the University and their results are going to be published in other papers (M. Arbabi, V. Artounian and F. Etesam, Personal communications). The screening results were conveyed to those who were screened positive and they were informed that they can receive mental health care from any center in the same or other hospitals/clinics. Preliminary evaluations showed that despite the high rates of mental health problems, the number of people who finally sought mental health care following screening, although a little higher than before, was still quite low. Thus, it was decided to provide consultation to anyone who was willing to receive them after the screening, regardless of the screening result.

In conclusion, formal screening should be regarded as a method among many other case identification strategies. For example, medical personnel such as general practitioners can identify mental health disorders during their routine practice. Collaborative care programs have provided an example of enhanced identification of mental health conditions in primary care..$^{59,60}$ On the other hand; conducting screening just for the sake of epidemiologic studies and ignoring the importance of providing effective and accessible interventions does not seem justifiable during such crises. Whenever screening becomes a component of an intervention program in the time of crisis in a country, a region or a hospital, it can facilitate patients' access to health services and improve their benefits. However, even in such situations, the abovementioned considerations should be taken into account before implementation and the pros and cons of mental health screening should be taken into account (Table 2). Moreover, original studies are highly needed to investigate the outcomes of implementing mental health screening and its efficacy and utility in crises such as the coronavirus epidemic. Unfortunately, studies which assess its benefits at the time of crises and disasters are lacking.

We made our best effort to include all existing relevant studies; however, this is still a narrative review with its own limitations. In this review, only studies relevant to some recent epidemics were assessed and other epidemics (like the swan influenza) were left out. On the other hand, there are discrepancies in the studies regarding the time of study (during or after the epidemics), and instruments used for identification of people with mental health problems which influence the conclusions of the review. There is a great need for original studies on the appropriate instruments and procedures for screening of mental health problems and their effectiveness during epidemics.

\section{Authors' Contribution}

VS developed the main idea. AM was the principal investigator. VS and AM wrote and review the manuscript.

\section{Conflict of Interest Disclosures}

The authors declare that there is no conflict of interests.

\section{Ethical Statement}

This study was a narrative review so human participants were not enrolled in study.

Not applicable

\section{Acknowledgements}

We would like to thank all the members of the crisis intervention team at the Department of Psychiatry in Tehran University of Medical Sciences who participated in planning and implementing interventions in the COVID-19 crisis, including Drs. Homayoun

Table 2. Pros and Cons of Screening for Mental Health Problems During Epidemics

\begin{tabular}{lc}
\hline Pros & Cons \\
\hline Most instruments are short and easy to administer. & The evidence for its utility is weak. \\
$\begin{array}{l}\text { Can lead to timely identification and referral of individuals who are otherwise } \\
\text { left behind }\end{array}$ & Can make demands which cannot be met \\
Can enhance help seeking and referral to reliable professionals/centers & Can lead to unjustified referral of a high number of false positives and/or \\
transient problems & Can lead to stigmatization \\
\hline Can provide an estimate for advocacy, policy and planning & Can be resource consuming and interrupt crisis services if not well \\
coordinated
\end{tabular}


Amini, Mohammad Arbabi, Valentin Artounian, Farnaz Etesam, Javad Mahmoudi Gharaei, Malek-farhad Malek, AliAkbar Nejatisafa, Nazila Shahmansouri, Maryam Tabatabaei and Seyyed Taha Yahyavi.

\section{References}

1. Luo M, Guo L, Yu M, Jiang W, Wang H. The psychological and mental impact of coronavirus disease 2019 (COVID-19) on medical staff and general public - a systematic review and meta-analysis. Psychiatry Res. 2020;291:113190. doi: 10.1016/j.psychres.2020.113190.

2. Serafini G, Parmigiani B, Amerio A, Aguglia A, Sher L, Amore M. The psychological impact of COVID-19 on the mental health in the general population. QJM. 2020;113(8):531-7. doi: 10.1093/qjmed/hcaa201.

3. Kontoangelos K, Economou M, Papageorgiou C. Mental health effects of COVID-19 pandemia: a review of clinical and psychological traits. Psychiatry Investig. 2020;17(6):491-505. doi: 10.30773/pi.2020.0161.

4. Elizarrarás-Rivas J, Vargas-Mendoza JE, Mayoral-García M, Matadamas-Zarate C, Elizarrarás-Cruz A, Taylor M, et al. Psychological response of family members of patients hospitalised for influenza A/H1N1 in Oaxaca, Mexico. BMC Psychiatry. 2010;10:104. doi: 10.1186/1471-244x-10104.

5. Blendon RJ, Benson JM, DesRoches CM, Raleigh E, TaylorClark K. The public's response to severe acute respiratory syndrome in Toronto and the United States. Clin Infect Dis. 2004;38(7):925-31. doi: 10.1086/382355.

6. Tansey CM, Louie M, Loeb M, Gold WL, Muller MP, de Jager J, et al. One-year outcomes and health care utilization in survivors of severe acute respiratory syndrome. Arch Intern Med. 2007;167(12):1312-20. doi: 10.1001/ archinte.167.12.1312.

7. Lancee WJ, Maunder RG, Goldbloom DS. Prevalence of psychiatric disorders among Toronto hospital workers one to two years after the SARS outbreak. Psychiatr Serv. 2008;59(1):91-5. doi: 10.1176/ps.2008.59.1.91.

8. Lee SM, Kang WS, Cho AR, Kim T, Park JK. Psychological impact of the 2015 MERS outbreak on hospital workers and quarantined hemodialysis patients. Compr Psychiatry. 2018;87:123-7. doi: 10.1016/j.comppsych.2018.10.003.

9. Maunder RG, Lancee WJ, Rourke S, Hunter JJ, Goldbloom D, Balderson K, et al. Factors associated with the psychological impact of severe acute respiratory syndrome on nurses and other hospital workers in Toronto. Psychosom Med. 2004;66(6):938-42. doi: 10.1097/01. psy.0000145673.84698.18.

10. Magill E, Siegel Z, Pike KM. The mental health of frontline health care providers during pandemics: a rapid review of the literature. Psychiatr Serv. 2020;71(12):1260-9. doi: 10.1176/appi.ps.202000274.

11. Mental health response to disasters and other critical incidents. 2017. Available from: https://www.bmj.com/ content/bmj/suppl/2017/06/30/357.jun21_2.j2981.DC1/ BP_emergency_response.pdf.

12. Zhang J, Wu W, Zhao X, Zhang W. Recommended psychological crisis intervention response to the 2019 novel coronavirus pneumonia outbreak in China: a model of West China Hospital. Precis Clin Med. 2020;3(1):3-8. doi: 10.1093/pcmedi/pbaa006.

13. Wind TR, Rijkeboer M, Andersson G, Riper H. The
COVID-19 pandemic: the 'black swan' for mental health care and a turning point for e-health. Internet Interv. 2020;20:100317. doi: 10.1016/j.invent.2020.100317.

14. North CS, Pfefferbaum B. Mental health response to community disasters: a systematic review. JAMA. 2013;310(5):507-18. doi: 10.1001/jama.2013.107799.

15. Kagee A, Tsai AC, Lund C, Tomlinson M. Screening for common mental disorders in low resource settings: reasons for caution and a way forward. Int Health. 2013;5(1):11-4. doi: 10.1093/inthealth/ihs004.

16. Raoofi A, Takian A, Akbari Sari A, Olyaeemanesh A, Haghighi H, Aarabi M. COVID-19 pandemic and comparative health policy learning in Iran. Arch Iran Med. 2020;23(4):220-34. doi: 10.34172/aim.2020.02.

17. World Health Organization (WHO): Clinical Care for Survivors of Ebola Virus Disease: Interim Guidance. Geneva: WHO; 2016.

18. Ying Y, Ruan L, Kong F, Zhu B, Ji Y, Lou Z. Mental health status among family members of health care workers in Ningbo, China, during the coronavirus disease 2019 (COVID-19) outbreak: a cross-sectional study. BMC Psychiatry. 2020;20(1):379. doi: 10.1186/s12888-02002784-w.

19. Naser AY, Dahmash EZ, Al-Rousan R, Alwafi H, Alrawashdeh HM, Ghoul I, et al. Mental health status of the general population, healthcare professionals, and university students during 2019 coronavirus disease outbreak in Jordan: a cross-sectional study. Brain Behav. 2020;10(8):e01730. doi: 10.1002/brb3.1730.

20. Shi L, Lu ZA, Que JY, Huang XL, Liu L, Ran MS, et al. Prevalence of and risk factors associated with mental health symptoms among the general population in China during the coronavirus disease 2019 pandemic. JAMA Netw Open. 2020;3(7):e2014053. doi: 10.1001/ jamanetworkopen.2020.14053.

21. Liu S, Yang L, Zhang C, Xiang YT, Liu Z, Hu S, et al. Online mental health services in China during the COVID-19 outbreak. Lancet Psychiatry. 2020;7(4):e17-e8. doi: 10.1016/ s2215-0366(20)30077-8.

22. Kang L, Ma S, Chen M, Yang J, Wang Y, Li R, et al. Impact on mental health and perceptions of psychological care among medical and nursing staff in Wuhan during the 2019 novel coronavirus disease outbreak: a cross-sectional study. Brain Behav Immun. 2020;87:11-7. doi: 10.1016/j. bbi.2020.03.028.

23. Chong MY, Wang WC, Hsieh WC, Lee CY, Chiu NM, Yeh WC, et al. Psychological impact of severe acute respiratory syndrome on health workers in a tertiary hospital. $\mathrm{Br} \mathrm{J}$ Psychiatry. 2004;185:127-33. doi: 10.1192/bjp.185.2.127.

24. Zerbini G, Ebigbo A, Reicherts P, Kunz M, Messman H. Psychosocial burden of healthcare professionals in times of COVID-19 - a survey conducted at the University Hospital Augsburg. Ger Med Sci. 2020;18:Doc05. doi: 10.3205/000281.

25. Que J, Shi L, Deng J, Liu J, Zhang L, Wu S, et al. Psychological impact of the COVID-19 pandemic on healthcare workers: a cross-sectional study in China. Gen Psychiatr. 2020;33(3):e100259. doi: 10.1136/gpsych-2020-100259.

26. Sim K, Huak Chan Y, Chong PN, Chua HC, Wen Soon S. Psychosocial and coping responses within the community health care setting towards a national outbreak of an infectious disease. J Psychosom Res. 2010;68(2):195-202. 
doi: 10.1016/j.jpsychores.2009.04.004.

27. Domínguez-Salas S, Gómez-Salgado J, Andrés-Villas M, Díaz-Milanés D, Romero-Martín M, Ruiz-Frutos C. Psychoemotional approach to the psychological distress related to the COVID-19 pandemic in Spain: a cross-sectional observational study. Healthcare (Basel). 2020;8(3):190. doi: 10.3390/healthcare8030190.

28. Mohammed A, Sheikh TL, Gidado S, Poggensee G, Nguku P, Olayinka A, et al. An evaluation of psychological distress and social support of survivors and contacts of Ebola virus disease infection and their relatives in Lagos, Nigeria: a cross sectional study--2014. BMC Public Health. 2015;15:824. doi: 10.1186/s12889-015-2167-6.

29. Taylor MR, Agho KE, Stevens GJ, Raphael B. Factors influencing psychological distress during a disease epidemic: data from Australia's first outbreak of equine influenza. BMC Public Health. 2008;8:347. doi: 10.1186/1471-24588-347.

30. Maunder RG, Lancee WJ, Balderson KE, Bennett JP, Borgundvaag B, Evans S, et al. Long-term psychological and occupational effects of providing hospital healthcare during SARS outbreak. Emerg Infect Dis. 2006;12(12):1924-32. doi: 10.3201/eid1212.060584.

31. Tanoue Y, Nomura S, Yoneoka D, Kawashima T, Eguchi A, Shi S, et al. Mental health of family, friends, and coworkers of COVID-19 patients in Japan. Psychiatry Res. 2020;291:113067. doi: 10.1016/j.psychres.2020.113067.

32. Zhang SX, Wang Y, Rauch A, Wei F. Unprecedented disruption of lives and work: health, distress and life satisfaction of working adults in China one month into the COVID-19 outbreak. Psychiatry Res. 2020;288:112958. doi: 10.1016/j.psychres.2020.112958.

33. Chua SE, Cheung V, Cheung C, McAlonan GM, Wong JW, Cheung EP, et al. Psychological effects of the SARS outbreak in Hong Kong on high-risk health care workers. Can J Psychiatry. 2004;49(6):391-3. doi: 10.1177/070674370404900609.

34. Yu HYR, Ho SC, So KFE, Lo YL. The psychological burden experienced by Hong Kong midlife women during the SARS epidemic. Stress Health. 2005;21(3):177-84. doi: 10.1002/smi.1051.

35. Wang C, Pan R, Wan X, Tan Y, Xu L, Ho CS, et al. Immediate psychological responses and associated factors during the initial stage of the 2019 coronavirus disease (COVID-19) epidemic among the general population in China. Int J Environ Res Public Health. 2020;17(5):1729. doi: 10.3390/ ijerph17051729.

36. Rehman U, Shahnawaz MG, Khan NH, Kharshiing KD, Khursheed M, Gupta K, et al. Depression, anxiety and stress among Indians in times of COVID-19 lockdown. Community Ment Health J. 2021;57(1):42-8. doi: 10.1007/ s10597-020-00664-x.

37. Rodríguez-Rey R, Garrido-Hernansaiz H, Collado S. Psychological impact and associated factors during the initial stage of the coronavirus (COVID-19) pandemic among the general population in Spain. Front Psychol. 2020;11:1540. doi: 10.3389/fpsyg.2020.01540.

38. Ji D, Ji YJ, Duan XZ, Li WG, Sun ZQ, Song XA, et al. Prevalence of psychological symptoms among Ebola survivors and healthcare workers during the 20142015 Ebola outbreak in Sierra Leone: a cross-sectional study. Oncotarget. 2017;8(8):12784-91. doi: 10.18632/ oncotarget.14498.

39. Li L, Wan C, Ding R, Liu Y, Chen J, Wu Z, et al. Mental distress among Liberian medical staff working at the China Ebola treatment unit: a cross sectional study. Health Qual Life Outcomes. 2015;13:156. doi: 10.1186/s12955-0150341-2.

40. Jeong H, Yim HW, Song YJ, Ki M, Min JA, Cho J, et al. Mental health status of people isolated due to Middle East respiratory syndrome. Epidemiol Health. 2016;38:e2016048. doi: 10.4178/epih.e2016048.

41. Lai J, Ma S, Wang Y, Cai Z, Hu J, Wei N, et al. Factors associated with mental health outcomes among health care workers exposed to coronavirus disease 2019. JAMA Netw Open. 2020;3(3):e203976. doi: 10.1001/ jamanetworkopen.2020.3976.

42. Chen R, Chou KR, Huang YJ, Wang TS, Liu SY, Ho LY. Effects of a SARS prevention programme in Taiwan on nursing staff's anxiety, depression and sleep quality: a longitudinal survey. Int J Nurs Stud. 2006;43(2):215-25. doi: 10.1016/j.ijnurstu.2005.03.006.

43. Quah SR, Hin-Peng L. Crisis prevention and management during SARS outbreak, Singapore. Emerg Infect Dis. 2004;10(2):364-8. doi: 10.3201/eid1002.030418.

44. Lu W, Wang H, Lin Y, Li L. Psychological status of medical workforce during the COVID-19 pandemic: a crosssectional study. Psychiatry Res. 2020;288:112936. doi: 10.1016/j.psychres.2020.112936.

45. Hawryluck L, Gold WL, Robinson S, Pogorski S, Galea S, Styra R. SARS control and psychological effects of quarantine, Toronto, Canada. Emerg Infect Dis. 2004;10(7):1206-12. doi: 10.3201/eid1007.030703.

46. Reynolds DL, Garay JR, Deamond SL, Moran MK, Gold W, Styra R. Understanding, compliance and psychological impact of the SARS quarantine experience. Epidemiol Infect. 2008;136(7):997-1007. doi: 10.1017/s0950268807009156.

47. Lee AM, Wong JG, McAlonan GM, Cheung V, Cheung C, Sham PC, et al. Stress and psychological distress among SARS survivors 1 year after the outbreak. Can J Psychiatry. 2007;52(4):233-40. doi: 10.1177/070674370705200405.

48. Wu P, Fang Y, Guan Z, Fan B, Kong J, Yao Z, et al. The psychological impact of the SARS epidemic on hospital employees in China: exposure, risk perception, and altruistic acceptance of risk. Can J Psychiatry. 2009;54(5):302-11. doi: 10.1177/070674370905400504.

49. Styra R, Hawryluck L, Robinson S, Kasapinovic S, Fones C, Gold WL. Impact on health care workers employed in high-risk areas during the Toronto SARS outbreak. J Psychosom Res. 2008;64(2):177-83. doi: 10.1016/j. jpsychores.2007.07.015.

50. Koh D, Lim MK, Chia SE, Ko SM, Qian F, Ng V, et al. Risk perception and impact of severe acute respiratory syndrome (SARS) on work and personal lives of healthcare workers in Singapore: what can we learn? Med Care. 2005;43(7):67682. doi: 10.1097/01.mlr.0000167181.36730.cc.

51. Liu N, Zhang F, Wei C, Jia Y, Shang Z, Sun L, et al. Prevalence and predictors of PTSS during COVID-19 outbreak in China hardest-hit areas: gender differences matter. Psychiatry Res. 2020;287:112921. doi: 10.1016/j. psychres.2020.112921.

52. Yoon MK, Kim SY, Ko HS, Lee MS. System effectiveness of detection, brief intervention and refer to treatment for the people with post-traumatic emotional distress by MERS: 
a case report of community-based proactive intervention in South Korea. Int J Ment Health Syst. 2016;10:51. doi: 10.1186/s13033-016-0083-5.

53. Ransing R, Ramalho R, Orsolini L, Adiukwu F, GonzalezDiaz JM, Larnaout A, et al. Can COVID-19 related mental health issues be measured? Brain Behav Immun. 2020;88:32-4. doi: 10.1016/j.bbi.2020.05.049.

54. Lee SH, Juang YY, Su YJ, Lee HL, Lin YH, Chao CC. Facing SARS: psychological impacts on SARS team nurses and psychiatric services in a Taiwan general hospital. Gen Hosp Psychiatry. 2005;27(5):352-8. doi: 10.1016/j. genhosppsych.2005.04.007.

55. Matsuishi K, Kawazoe A, Imai H, Ito A, Mouri K, Kitamura $\mathrm{N}$, et al. Psychological impact of the pandemic (H1N1) 2009 on general hospital workers in Kobe. Psychiatry Clin Neurosci. 2012;66(4):353-60. doi: 10.1111/j.14401819.2012.02336.x.

56. Robertson E, Hershenfield K, Grace SL, Stewart DE. The psychosocial effects of being quarantined following exposure to SARS: a qualitative study of Toronto health care workers. Can J Psychiatry. 2004;49(6):403-7. doi: 10.1177/070674370404900612.

57. Chua SE, Cheung V, McAlonan GM, Cheung C, Wong JW, Cheung EP, et al. Stress and psychological impact on SARS patients during the outbreak. Can J Psychiatry. 2004;49(6):385-90. doi: 10.1177/070674370404900607.

58. Reported Cases and Deaths by Country or Territory. Available from: https://www.worldometers.info/ coronavirus/\#countries.

59. Sharifi V, Shahrivar Z, Zarafshan H, Ashkezary SB, Stuart E, Mojtabai R, et al. Collaborative care for child and youth mental health problems in a middle-income country: study protocol for a randomized controlled trial training general practitioners. Trials. 2019;20(1):405. doi: 10.1186/s13063019-3467-4.

60. Bentham W, Vannoy SD, Badger K, Wennerstrom A, Springgate BF. Opportunities and challenges of implementing collaborative mental health care in postKatrina New Orleans. Ethn Dis. 2011;21(3 Suppl 1):30-7. 